\title{
Tradução, (in)fidelidade e gênero num conto de Moacyr Scliar ${ }^{1}$
}

Rosemary Arrojo

Binghamton University, New York, U.S.A

O senso comum em geral associa as traduções e os tradutores a diferentes formas de traição. Neste ensaio pretendo me concentrar na forma pela qual o tema da traição do tradutor é tratado, com base na representação de um triângulo amoroso envolvendo a competição de dois homens pelo amor de uma mulher. O objeto de minha análise será um conto de Moacyr Scliar, intitulado "Notas ao Pé da Página", publicado em 1995. Creio que esse tipo de leitura pode nos auxiliar a compreender a reputação geralmente negativa dos tradutores numa cultura que celebra originais e que tende a desconfiar de qualquer atividade que possa interferir com a sua suposta integridade. Também pode nos ajudar a compreender as motivações das principais teorias de tradução que sempre se interessaram em desenvolver mecanismos para o controle e a disciplina dos tradutores e de suas intervenções nos textos que necessariamente têm que reescrever.

Common sense has often associated both translations and translators with different forms of betrayal. In this paper I intend to focus on how the theme of betrayal in translation is treated in terms of a love triangle, in which the translator's "unreliable" handling of the original is associated with some form of competition with the author for the love of a woman. The object of my analysis will be a short story by Moacyr Scliar entitled "Notas ao Pé da Página", first published in Brazil in 1995. I believe that such an analysis may help us further understand the often negative reputation translators seem to have in a culture that worships originals and tends to distrust any activity that somehow "touches" them. It may also help us reflect on why mainstream translation theories have always been so interested in controlling and disciplining translators and their interventions in the texts they necessarily have to rewrite.

O senso comum com freqüência associa as traduções e os tradutores a diferentes formas de traição, como sugerem alguns conhecidos aforismos ("traduttori-tradittori", "les belles infidels"). Em textos anteriores tentei

\footnotetext{
${ }^{1}$ Versões preliminares deste texto foram apresentadas em conferências no Brasil (PUC-Rio, Rio de Janeiro, julho de 2003) e nos Estados Unidos (Emory University, Atlanta, Geórgia, março de 2004).
} 
explorar a forma pela qual alguns textos de ficção representam as relações complexas que geralmente se estabelecem entre originais e suas reproduções, bem como entre autores, tradutores, intérpretes e leitores (ARROJO, 1986, 1993, 1995, 2002, 2003a, 2003b). O que tem inspirado a escritura desses ensaios é a crença de que as visões sobre textos e suas reproduções, bem como sobre aqueles encarregados de produzi-las, que se encontram implicita ou explicitamente plasmadas em alguns enredos de ficção associados a diferentes tradições literárias (escritos por autores como Borges, Poe, Kafka, Kosztolanyi, Calvino, Saramago), constituem, em última análise, um reflexo fiel das formas pelas quais a cultura tende a lidar com a reprodução de originais e com aqueles que se dedicam a esse tipo de atividade textual. Ao mesmo tempo, creio que o exame desses textos de ficção pode nos auxiliar a compreender os fatores responsáveis pela construção de uma certa resistência generalizada à tradução e da reputação negativa que freqüentemente se associa aos tradutores em nosso contexto cultural, que ainda pensa os chamados "originais" como depósitos estáveis e confiáveis das intenções autorais e que, portanto, tende a desconfiar de qualquer atividade que possa desestabilizá-los. Conseqüentemente, o exame desses textos também pode nos auxiliar a compreender as razões pelas quais as principais teorias de tradução sempre se empenharam em proteger os originais das investidas indesejadas dos tradutores e em encontrar formas de discipliná-los.

Neste texto, pretendo me concentrar na forma pela qual o velho tema da traição do tradutor assume matizes explicitamente sexuais quando se associa ao tipo de competição que ocorre entre homens pelas atenções (e pela posse) de uma mulher atraente num conto instigante, intitulado Notas ao Pé da Página, de Moacyr Scliar (1995). ${ }^{2}$ Um texto importante para esta discussão é o conhecido ensaio de Lori Chamberlain, Gender and the Metaphorics of Translation (1992), que discute a sexualização da tradução refletida, por exemplo, na conhecida noção das "belas infiéis", que compara as traduções às mulheres e que determina, portanto, que assim "como as mulheres, as traduções podem

\footnotetext{
${ }^{2}$ Agradeço a minha ex-aluna Maria Aparecida Fernandes (IEL-UNICAMP) por ter me introduzido ao texto de Scliar.
} 
ser bonitas ou fiéis" (SCLIAR, 1995, p. 58). ${ }^{3}$ Conseqüentemente, para que possam se manter fiéis, as traduções, como as mulheres, devem ser necessariamente feias, desinteressantes, ou inadequadas de alguma forma. Como observa Chamberlain, esse aforismo

deve sua longevidade - foi cunhado no século XVII - não apenas à semelhança fonética; o que lhe dá uma aparência de verdade é o fato de ter capturado uma cumplicidade cultural entre as questões de fidelidade na tradução e no casamento. Para "as belas infiéis", a fidelidade se define através de um contrato implícito entre a tradução (como mulher) e o original (como marido, pai, ou autor). (Idem)

O que interessa a Chamberlain na exploração das implicações dessa comparação é a assimetria de poder que constitui a relação entre "a tradução (como mulher) e o original (como marido, pai, ou autor)" (idem). Como afirma, o que está em jogo nessa comparação é o mesmo princípio de dois pesos e duas medidas que geralmente define a base que caracteriza os casamentos tradicionais: "a esposa/tradução 'infiel' é publicamente julgada por crimes que o marido/original é, por lei, incapaz de cometer" (idem).

É precisamente uma expansão (e uma reinterpretação) desse triângulo amoroso, envolvendo o texto (como mulher), o autor e o tradutor, que dá sustentação a "Notas ao Pé da Página”, de Moacyr Scliar. Como o título sugere, o conto é composto de notas de tradutor, cinco no total, que aparecem no rodapé das cinco páginas vazias onde deveria se encontrar a tradução do original. Enquanto a tradução e, conseqüentemente, enquanto o original e seu autor não estão acessíveis a nós, leitores, é a escritura do tradutor que constitui o texto do conto que lemos. Assim, embora o narrador de Scliar represente a única voz autoral do conto, ou seja, embora o que lemos seja exclusivamente o texto do tradutor, este escreve dentro dos limites do único espaço textual que em geral se destina aos tradutores: o rodapé da página. Através de suas notas descobrimos que se referem à tradução que preparou dos diários de um poeta já morto. E é supostamente com o objetivo de esclarecer alguns pontos do texto traduzido que essas notas acabam por (indevidamente) nos revelar detalhes da biografia do poeta cujos diários constituem o original a que não temos acesso, curiosamente

${ }^{3}$ Esta e todas as outras traduções de textos citados em inglês são minhas. 
nem através da tradução. Ficamos sabendo, por exemplo, que o poeta costumava ser ingrato (p. 371), de "desmedida ambição" (p. 372) e de difícil relacionamento (p. 373). Também somos informados sobre seus esforços humilhantes para conseguir cair nas graças do tradutor que, como ficamos sabendo, tinha uma reputação que o "enquadrava" na "categoria" das pessoas importantes (p. 372). Além disso, ficamos sabendo que a última vez que os dois se encontraram, pouco antes da morte do poeta, este, como sempre, "veio com a bajulação habitual" e confessou ao tradutor que gostava até mesmo das suas notas de rodapé (p. 375). E o que é ainda mais peculiar, somos informados acerca dos detalhes do triângulo amoroso que envolveu o tradutor, o poeta e N., sua amante, que abandonou este para se casar com o tradutor. As notas de rodapé também nos informam que o poeta, o autor invisível e já morto, não era apenas um homem solitário e sem muitos recursos que ficou desesperado ao perder a amante, mas que também atribuía a maior parte de seu "relativo" sucesso ao talento e à compaixão do tradutor.

Em primeiro lugar, o que chama atenção no enredo de Scliar é o fato de que nos apresenta um tradutor que, de acordo com sua própria narrativa, é bastante competente e, podemos concluir, especialmente eficiente em seu trabalho, ou, pelo menos, somos levados a crer no seu talento de tradutor fiel e insistentemente solicitado pelo poeta, que desejava ver seus textos traduzidos. E apesar disso, o tradutor, sem dúvida, abusa do espaço que convencionalmente lhe é dado ao pé das páginas em que deveríamos encontrar sua tradução. Considerando o desencontro entre o conteúdo dessas notas e sua suposta reputação de excelente tradutor, podemos dizer que estamos lidando com um tradutor que é, ao mesmo tempo, fiel e infiel - fiel aos originais do poeta, mas infiel mesmo assim. Levando em conta essas circunstâncias, como devemos nós, leitores, reagir ao enredo de Scliar? Deveríamos considerar que alguma forma de infidelidade, ou abuso, é o destino inescapável dos tradutores, mesmo daqueles que parecem capazes de realizar seu trabalho de forma adequada? Ou estaria Scliar celebrando a "visibilidade" corajosa de seu poderoso tradutor?

Antes de tentar elaborar uma possível resposta, parece claro que o conto brinca, de forma bem-humorada, com os velhos clichés que envolvem as noções de propriedade, fidelidade e traição e suas implicações para as relações tradicionalmente estabelecidas entre autores, originais, tradutores e traduções. As relações de poder que 
geralmente organizam essas noções em oposições claras e hierarquizadas parecem ter sido radicalmente alteradas em "Notas ao Pé da Página". Enquanto o senso comum geralmente espera que os tradutores (e, particularmente, aqueles que se envolvem com textos literários) façam seu trabalho idealmente "invisível" à sombra dos autores aos quais devem fidelidade, o narrador de Scliar assume uma postura claramente autoral. Como já foi observado, por exemplo, é a escritura do tradutor, apenas marginalmente associada ao original, que constitui o texto visível que temos para ler no conto de Scliar. Além do mais, o autor nos apresenta a um tradutor auto-confiante e influente, que não apenas suplanta o poeta fraco e inseguro, ao qual supostamente deve respeito e fidelidade, mas que também é responsável, em grande parte, pelo modesto sucesso alcançado pelos textos que concordou em traduzir.

Além do mais, o narrador/tradutor se apresenta como a figura masculina forte e poderosa que conquista a mulher-prêmio no triângulo amoroso que define o conto, e no qual N. representa a óbvia "bela infiel". Como metáfora do texto, ou daquilo que o poeta pretende (mas não consegue) possuir e controlar, N. representa a instabilidade de significados e a vocação para a infidelidade que caracteriza a escritura, sempre pronta para se dar e ser possuída por outros leitores. ${ }^{4}$ Em outras palavras, como vimos, para que o poeta consiga publicar seu livro, é necessário que permita que o editor interfira em seu texto ou, como sugere a metáfora do texto como mulher, é necessário que concorde em dividir, de alguma forma, o controle sobre seu texto (e sua amante) com o editor. Aliás, o poeta também precisa concordar em dividir com o tradutor o prazer autoral de possuir seu texto/mulher. Como sugere o narrador/tradutor ao comentar a "ansiedade" com que lhe aguardava o poeta, este colocou N. "à [sua] inteira disposição": "de fato, ela foi gentilíssima; seu desvelo era para mim - recém-saído de um traumático

\footnotetext{
${ }^{4}$ Como ficamos sabendo, quando N. conheceu o poeta na França, ela trabalhava como secretária na pequena editora que finalmente concordou em publicar a primeira coleção de poemas do poeta. Segundo o narrador, "o relativo sucesso dessa obra se deve, ao menos em parte, aos esforços da própria N. Foi ela quem obteve do proprietário da editora (e para isso teve de prestar-lhe certos favores) a relutante concordância para um empreendimento que, do ponto de vista mercadológico, representava uma aventura de desfecho imprevisível" (p. 371).
} 
divórcio - amparo e consolo" (p. 372). Contudo, e o que é ainda mais significativo para a construção da metáfora do texto como mulher e suas implicações para as relações que estabelece com o autor e o tradutor, N., apesar de sua vocação para a infidelidade, abandona o poeta para se casar com o tradutor. Ou seja, é com o poderoso tradutor, e não com o poeta fraco, que N. assume o compromisso de exclusividade sexual e total fidelidade. Ou seja, é o tradutor quem finalmente tem o direito de possuir e controlar os movimentos da bela, agora (supostamente) fiel para sempre.

Os leitores familiarizados com teorias de tradução contemporâneas podem associar o enredo de Scliar a alguns textos recentes sobre interpretação, leitura e tradução. O trabalho de Lawrence Venuti sobre a (in)visibilidade do tradutor é, com certeza, um dos primeiros que pode ocorrer aos interessados nos estudos de tradução. Como se sabe, o principal interesse teórico de Venuti tem sido a exploração do que considera o "eclipse do trabalho do tradutor" e, como tem freqüentemente argumentado, a tradução continua a ser "uma prática invisível, em todos os lugares, inescapavelmente presente, mas raramente reconhecida, quase nunca incluída nas discussões sobre as traduções que inevitavelmente lemos" (1992, p. 1). Venuti tem se empenhado em revelar as "assimetrias" que envolvem a prática tradutória. Como sugere na introdução a The Scandals of Translation - Towards an Ethics of Difference, seu "principal pressuposto" é, talvez, "o maior escândalo da tradução: assimetrias, iniqüidades, relações de dominação e dependência que existem em todo ato tradutório na medida em que coloca o traduzido a serviço da cultura que traduz" (1998, p. 4). Além disso, o principal objetivo de seu trabalho tem sido não apenas conscientizar os tradutores e os especialistas em tradução acerca desses "escândalos", mas, também, propor e defender estratégias de tradução que possam contribuir para mudar o status quo. Levando em conta esse tipo de reflexão, estaria Scliar, em algum nível, revelando, através da inversão de atribuições e papéis tradicionalmente associados à escritura dita "original" e à tradução, a assimetria de poder que geralmente dá sustentação à relação tradutor/autor? Estaria Scliar, através de seu narrador, parodiando a figura do tradutor forte e poderoso associada, por exemplo, ao trabalho de Haroldo e Augusto de Campos?

Também poderíamos relacionar o conto de Scliar a alguns dos mais importantes pensadores geralmente associados a teorias textuais 
pós-estruturalistas como Michel Foucault e Roland Barthes, cujos textos sobre a "morte" do autor e o papel autoral do leitor produtivo constituem exemplos apropriados da celebração pós-nietzscheana da leitura concebida como estratégia de construção, e não de recuperação, de significados. Assim, de acordo com Barthes, "não se deve nenhum respeito 'vital' ao Texto, [que] pode ser lido sem a garantia de seu pai, já que a restituição do intertexto paradoxalmente abole qualquer legado" (1977, p. 161). E a partir do momento em que o pai do Texto se torna uma presença desnecessária na cena da leitura, cabe ao leitor/ intérprete decidir o que fazer em relação ao papel que deve desempenhar, na leitura, o autor enfraquecido. Este, segundo Barthes, pode apenas "regressar" ao seu Texto como um "convidado", que o leitor pode, ou não, querer entreter: ele se torna, por assim dizer, um "autor de papel: sua vida deixa de ser a origem de suas ficções, e passa a ser uma ficção que contribui para a sua obra" (idem). De forma semelhante, Michel Foucault transformou o antes todo poderoso Autor numa mera "função", ou "num certo princípio funcional com o qual, em nossa cultura, limitamos, excluímos e fazemos escolhas; em resumo, com o qual impedimos a circulação livre, a manipulação livre, a composição, a decomposição e a recomposição livres da ficção" (1979, p. 159). Novamente, se associarmos esse tipo de teorização ao conto, poderíamos dizer que Scliar estaria interessado em ficcionalizar essas noções de autoria e interpretação? Estaria Scliar interessado em ilustrar a "força" do tradutor e a "morte" do autor, defendidas pelo pensamento pós-estruturalista?

Outra leitura importante que podemos associar ao conto é a proposta por Jacques Derrida com base no conhecido A Tarefa do Tradutor, de Walter Benjamin, na qual o filósofo francês amplia a revisão radical da relação tradicionalmente estabelecida entre originais e traduções sugerida por Benjamin. Ao desconstruir a concepção logocêntrica do original como presença e ao expandir a noção benjaminiana da tradução como sobrevida, Derrida redimensiona a relação que tradicionalmente se estabelece entre original e tradução, e entre autor e tradutor, relação essa que não mais se pode pautar pelas noções convencionais de fidelidade e originalidade. Como argumenta, se "a estrutura da obra é "sobrevida", a "divida do tradutor" não se refere ao "sujeito autor do texto original - morto ou mortal, o morto, ou o 'boneco' do texto". Refere-se, sim, àquilo "que representa a lei formal na imanência do texto original", ou seja, "a dívida não envolve 
a restituição de uma cópia ou de uma boa imagem, uma representação fiel do original", pois "este, o sobrevivente, está, ele próprio, envolvido num processo de transformação” (1985, p. 182-183).

Com base nessas possíveis associações entre o conto de Scliar e algumas noções de texto e de tradução vinculadas à pós-modernidade, poderíamos sugerir que o conto defende, de alguma forma, a visibilidade do tradutor e que estaria propondo uma reconfiguração das relações de poder que em geral aproximam e afastam originais e traduções, autores e tradutores? Em outras palavras, seria aceitável, e até desejável, que o tradutor tomasse posse do texto-mulher, e que esta, a incorrigivel "bela infiel", abandonasse o autor para se casar com o tradutor? Afinal, como poderíamos argumentar, no conto de Scliar, encontramos apenas a perspectiva e a voz do tradutor. Mas seria essa perspectiva confiável? A ausência sumária da voz do poeta traduzido e o uso descaradamente indevido que faz o tradutor/narrador do espaço textual que lhe é reservado parecem ser o reflexo do ressentimento do tradutor em relação ao espaço limitado e ao papel marginal que a tradição lhe reserva no mundo das letras. Em outras palavras, embora o conto de Scliar supostamente nos ofereça o ponto de vista do tradutor, parece, ao mesmo tempo, estar implicitamente defendendo o personagem autor ausente contra seu tradutor (inadequadamente) visível. Em suma, como poderíamos confiar no narrador de Scliar ao considerarmos o tratamento nada profissional que concede ao autor que traduz? Como poderíamos não nos solidarizar com o poeta morto cuja amante o tradutor acaba seduzindo?

A partir desse ângulo, poderíamos concluir que o tradutor personagem de Scliar nos oferece uma perspectiva perversa sobre o suposto desejo do tradutor de tomar posse do texto alheio, uma perspectiva que se encontra inevitavelmente associada à preocupação do autor em relação à defesa de seu texto contra interferências externas. Contudo, podemos acrescentar que embora o conto retrate a reputação do tradutor de forma tão negativa, também reconhece, de forma explícita, o seu papel essencialmente autoral. Na verdade, poderíamos argumentar que é precisamente em função do reconhecimento desse papel autoral que há motivo para preocupação. O que especialmente chama atenção no conto de Scliar é a natureza dessa preocupação e a relação direta que a mesma constrói entre texto e mulher. Ou seja, uma das mensagens implícitas no enredo é a associação direta que se 
estabelece entre o desejo do autor de defender seus textos da interferência alheia e o desejo do homem de manter suas mulheres a salvo da influência de outros homens. Infelizmente, contudo, essa "mensagem" não envolve apenas um autor preocupado com a integridade de seus textos e um tradutor de conduta ética duvidosa. Envolve, também, a representação da figura feminina essencialmente como objeto do desejo masculino, comparável ao texto, e particularmente ao texto concebido pelo pensamento pós-estruturalista, ou seja, volúvel, instável e essencialmente infiel, até que encontre um leitor forte o suficiente para estabilizá-lo, ainda que temporariamente, num implícito contrato de leitura, em que os principais papéis repetem aqueles encontrados no estereótipo do casamento tradicional.

Levando em conta a metáfora do texto/mulher e sua relação com o tradutor como usurpador, poderíamos concluir que, ao desconstruirmos esse tipo de representação da atividade tradutória, tão arraigada no imaginário de nossa cultura, deveríamos também refletir como as relações geralmente assimétricas que se estabelecem entre autores e tradutores, originais e traduções, se encontram diretamente ligadas a outras assimetrias, como, por exemplo, aquela que tem definido as relações entre os gêneros numa cultura ainda obcecada pela possibilidade de sentidos originais e oposições binárias.

\section{Referências Bibliográficas}

ARROJO, Rosemary. Oficina de Tradução - A Teoria na Prática. São Paulo: Ática, 1986. 85 p.

ARROJO, Rosemary. A Tradução e o Flagrante da Transferência: Algumas Aventuras Textuais com Dom Quixote e Pierre Menard. In: ARROJO, R. Tradução, Desconstrução e Psicanálise. Rio de Janeiro: Imago, 1993. p. $151-176$.

ARROJO, Rosemary. Translation and Postmodernism in Calvino's Se una notte d'inverno un viaggiatore. La traduzione: Saggy e documenti II, Libri e riviste d'Italia, Ministero per i Beni Culturali e Ambientali, divisione Editoria, p. 41-56, 1995.

ARROJO, Rosemary. Writing, Interpreting and the Power Struggle for the Control of Meaning. In: TYMOCZKO, M.; GENTZLER, E. (Ed.). Translation 
and Power. Amherst and Boston: University of Massachusetts Press, 2002. p. 63-79.

ARROJO, Rosemary. The Power of Originals and the Scandal of Translation - A Reading of Edgar Allan Poe's "The Oval Portrait". In: PÉREZ, M. C. (Ed.). Translation and Ideology. Manchester: St. Jerome, 2003a. p. 165-180.

ARROJO, Rosemary. A Relação Exemplar entre Autor e Revisor (e Outros Trabalhadores Textuais Semelhantes) e O Mito de Babel: Alguns Comentários sobre História do Cerco de Lisboa, de José Saramago. D.E.L.T.A. - Revista de Documentação de Estudos em Lingüistica Teórica e Alicada, v. 19: Especial, p. 176-193, 2003b.

BARTHES, Roland. From Work to Text. In: Image, Music, Text. Trad. Stephen Heath. New York: Hill and Wang, 1977. p. 155-164.

CHAMBERLAIN, Lori. Gender and the Metaphorics of Translation. In: VENUTI, L. (Ed.). Rethinking Translation - Discourse, Subjectivity, Ideology. Londres e Nova York: Routledge, 1992. p. 57-74.

DERRIDA, Jacques. Des Tours de Babel. Trad. Joseph F. Graham. In: GRAHAM, J. F. (Ed.). Difference in Translation. Ithaca e Londres: Cornell University Press, 1985. p. 165-208.

FOUCAULT, Michel. What Is an Author? In: HARARI, J. (Ed.). Textual Strategies - Perspectives in Post-Structuralist Criticism. Ithaca: Cornell University Press, 1979. p. 141-160.

SCLIAR, Moacyr. Notas ao pé da página. In: Contos Reunidos. São Paulo: Companhia das Letras, 1995. p. 371-375.

VENUTI, Lawrence. The Scandals of Translation - Towards an Ethics of Difference. Londres e Nova York: Routledge, 1998. 